\title{
Os Conjurados de 1789 e a Escravidão
}

José Geraldo Vidigal de Carvalho

Universidade Federal de Ouro Preto/Mariana

No que tange ao posicionamento dos Conjurados de 1789 quanto à escravidão, as opiniões dos analistas da História são divergentes. Uma vez expostas assertivas de alguns autores, chega-se, com base nos Autos de Devassa da Inconfidência Mineira e outros documentos, a conclusões que revelam o perigo de afirmativas sem a visualização global de um contexto. O diagnóstico da real situação da segunda metade do século dezoito conduz a uma mais pertinente compreensão da atitude dos que pugnavam ardorosamente na Minas Colonial, por uma nova estrutura sócio-econômica. A presença atuante da Igreja, sobretudo por meio das Irmandades, havia ocasionado um fato marcante que é olvidado, o qual leva a situar melhor o ponto de vista de Tiradentes e seus companheiros, entre os quais cinco sacerdotes, que foram figuras de destaque. Não se focaliza com a devida ênfase que o número de alforriados já era então notável. Eis aí um referencial importantíssimo.

Na História Geral da Civilização Brasileira, sob a responsabilidade de vários especialistas, lemos o seguinte sobre os participantes da Conjuração Mineira: "Surgiu a questão da escravidão, mas não como instituição incompatível com a nova República, que pretendiam fundar. Estavam tão pouco imbuídos do humanitarismo do seéculo XVIII que a idéia não thes ocorreu. Os escravos apresentavam-se como um possível obstáculo aos seus intentos. Sendo muito maior o número de pretos, poderiam aproveitar-se da situação e matar os brancos. Alvarenga sugeriu então que se 1hes concedesse a liberdade, objetando Maciel que seria desorganizar os trabalhos das minas e da lavoura. Com sua habitual inconsequiência, Alvarenga respondeu que se libertassem apenas os mulatos. Os inconfidentes não se detiveram no exame de tão importante questão que ficou em sus- 
penso" (1). João Camilo de Oliveira Torres afirmou na sua História de Minas Gerais: "A respeito da abolição da escravatura, houve certa desconversa. Não faltou quem temesse que o levante provocasse, por sua vez, uma revolução dos pretos" (2). A divulgada coleção Grandes Personagens da Nossa História, organizada por uma brilhante equipe de pesquisadores, historiógrafos, redatores, fotógrafos, e cartógrafos sob a liderança do consagrado historiador Sérgio Buarque de Holanda" (3), faz este registro ao tratar do Alferes Joaquim José da Silva Xavier e seus associados: “... debatem o fim da escravidão, mas deixam a questão em suspenso, já que alguns não acham o momento oportuno (4), Lúcio José dos Santos (5), Kenneth Maxwell (6) e outros limitam-se a sintetizar o que respondeu José Álvares Maciel no interrogatório de 26 de novembro de 1789, no Rio de Janeiro (7).

Aqui estão os textos incisivos que ostentam não ter havido dubiedade por parte dos envolvidos na revolta nas Gerais. Eles não eram racistas, não pretendiam distâncias grupais e nem intentavam isolar os negros do processo libertário. Não houve tergiversação quanto à libertação como tal. Jerônimo de Castro e Souza, Alferes do Regimento de Cavalaria Auxiliar da Capitania do Rio de Janeiro, asseverou que, numa noite do mês de abril de 1789, "foi ele, testemunha, à casa de Valentim Lopes da Cunha, que mora na rua do Ouvidor... aí encontrou a Joaquim José da Silva Xavier, Alferes do Regimento de Cavalaria paga de Minas Gerais". (8) Narra como este disse que "ele receava houvesse levante na Capitania de Minas Gerais em razão da derrama que se esperava; porque havia no povo da dita Capitania grande número de brancos, mulatos e negros... (grifo nosso)... e que seria em semelhante circunstância fácil o dito levante". (9) Esta declaração ele a confirmou em carta de denúncia, na qual escreve ter Joaquim José da Silva Xavier falado que "pela derrama que estava para se por fim em Minas, que pensava haver levante no povo, porque havia grande

(1) - Diversos, Inquietação revolucionária no Sul: Conjunração Mineira in: História Geral da Civilização Brasileira, Vol. I, A Época Colonial; Tomo 2, Administração, Economia, Sociedade, 2a Edição, São Paulo, 1968, Difusão Européia do Livro, p. 399.

(2) - João Camilo de Oliveira Torres, História de Minas Gerais, 3ำ volume, Belo Horizonte, Difusão Pan-Americana do Livro, s/d. p. 669.

(3) - Diversos, Grandes Personagens de Nossa História, vol. I, São Paulo, Abril Cultural Ltda. 1969. p. 3.

(4) - Idem, ibidem, p. 228

(5) - Lúcio José dos Santos, A Inconfidência Mineira, Belo Horizonte, Imprensa Oficial, 1972, p. 352.

(6) - Kenneth Maxwell, A Devassa da Devassa, Rio de Janeiro, Editora Paz e Terra S. A., 1978, p. 151-152.

(7) - Autos de Devassa da Inconfidência Mineira, vol. IV, Rio de Janeiro, Ministério da Educação, 1936, p. 398./ADIM, IV, 398. - Assim será feita a referência até o final.

(8) - ADIM, III, 258.

(9) - Idem, ibidem. 
número de brancos, pardos e negros (grifo nosso)... com que thes seria fácil o levante". (10) Seria, assim, um movimento eminentemente popular, do qual todos participariam e passariam depois a viver igualmente. A prova de que os menos letrados não seriam utilizados apenas como instrumentos, mas se beneficiariam com as medidas a serem adotadas é que, deixou claro o Pe. Corrêa de Toledo e Mello, a legislação seria em tudo vantajosa para todos. Ele com efeito, certificou a Joaquim Silvério "ter visto parte das leis fabricadas pelo Desembargador Gonzaga, em tudo favoráveis aos povos..." (11) Quando se penetra no meandro do pensamento revolucionário se percebe que, na República populista arquitetada não havia lugar para esdrúxulas distinções por causa de algo acidental como a pigmentação da pele. Isto chocaria com a mentalidade liberal que norteava os corajosos passos dos corifeus de uma ordem social igualitária. Esta, seja lembrado, se inspirava fortemente também no iluminismo. A Universidade de Coimbra, exerceu papel decisivo na divulgação dos ideais iluministas e foi nesta instituição que se formou a elite cultural mineira, a qual amadureceria exatamente na época da Conjuração. Acrescente-se que muito influenciou a conjuração mineira o exemplo da Independência dos Estados Unidos da América, como fato em si e como reflexo da filosofia européia. A Constituição Americana era conhecida. (12) O cônego Luiz Vieira da Silva imergiu na estratégia ianque. (13) Ele "se instruía nas leis e governo da América Inglesa". (14) Ora, quer a Filosofia das Luzes, quer a reflexão Americana tinham um leit motiv constante: a liberdade. Tal estado de espírito era passado às camadas mais baixas. Os próprios negros e mulatos conviviam com tais articulações. Basílio de Brito faz entrever isto no seu depoimento (15) ao narrar que a notícia da dita almejada sublevação e motim já grassava por muitas pessoas. Ele mesmo já havia escutado de pessoas de côr "que estava para haver um levante nas Minas". (16)

Além do mais, registrou que, na mesma Estalagem das Cabeças, em Vila Rica, "andando ele testemunha a passear na varanda, dela ouviu dizer a um mulato do Serro do Frio por nome Crispiniano que estava, conversando com outro mulato por nome Raimundo Corrêa, major do Regimento dos Pardos do Tejuco, que desta vila se tinha escrito para a Capitania de S. Paulo, para que já se levantassem e não pagassem os dízimos".

(10) - Idem, 267.

(11) - ADIM, IV, 193.

(12) - ADIM, L, 254.

(13) - Cônego José Geraldo Vidigal de Carvalho. Ideologia de Raízes Sociais do Clero da Conjuração - Século XVIII - Minas Gerais, Viçosa, Imprensa Universitária da UFV, 1978, p. 35-39.

(14) - ADIM, IV, 307.

(15) - ADIM. III, 303.

(16) - Idem, ibidem. 
(17) Almir de Oliveira, com razão, é taxativo: “... a Inconfidência Mineira não foi um "movimento de classes elevadas". Nem um projeto da república, na qual os negros e mulatos fossem relegados a uma situação inferior. Não há uma palavra que autorize semelhante asserto. Ao contrário, o que se vê é o desejo de se libertarem os escravos negros e mulatos. É o desejo de integrá-los na revolução como elementos ativos dela. É a ação de proselitismo desenvolvida no meio deles. Os inconfidentes não ignoravam a força que representavam negros e mestiços na Capitania. Eram numerosos. Dariam bom auxílio. E depois, é natural que, mesmo a título de compensação, fossem eles integrados como homens livres na nova sociedade, forjada sob a inspiração de idéias democráticas”. (18)

Aliás, nesta quadra, inúmeros eram os escravos forros, libertados através mormente das Irmandades do Rosário e das Mercês. No Arquivo Eclesiástico da Arquidiocese de Mariana há livros de assentamentos destas Irmandades e numerosas cartas de alforria, que relevam já existir uma significativa massa de libertos. Os Autos de Devassa também mostram pessoas que usufruíram de tal privilégio. Foram chamados a depor diversos forros como José Moreira, (19) José Lopes Ribeiro, (20) Manoel da Costa Capanema. (21) Adite-se que o sistema de alforria era lento, mas irreversível. A prova disto é a estatística que João Emanuel Pohl divulga. (22) Vinte e oito anos depois, em 1817, havia no Brasil 660.000 negros e mulatos livres e 2,100.000 escravos. Em consequência, mais da metade era de manumissos.

A passagem sumamente expressiva dos Autos de Devassa e que vem às vezes, servindo de suporte para uma colocação generalizadora sobre o pensar dos patriotas mineiros são os dizeres de José Álvares Maciel. O célebre ouro-pretano assim se manifestou: "... havia um grande obstáculo, que era o número de negros ser maior, que o dos brancos e que por conseguirem liberdade tomariam o partido contrário, matando os brancos e suposto que o dito Coronel Alvarenga quis remediar isto, dizendo, que lhes daria primeiro a liberdade, sempre ele respondente lembrou, que não ficaria em boa ordem o serviço das minas e tudo o mais lembrando além disso, que ainda não se fizesse, o que o citado Coronel Alvarenga aconselhava, que era forrarem-se só os crioulos e mulatos o que não suce-

(17) - Idem, ibidem

(18) - Almir de Oliveira, As Duas Inconfidências, Juiz de Fora, Ediçôes Caminho Novo, 1979, p. 41.

(19) - ADMI, II, 329.

(20) - ADID, III, 451.

(21) - Idem, 468.

(22) - João Emanuel Pohl, Viagem no Interior do Brasil, Primeira parte, Rio de Janeiro, Ministro da Educação e Saúde, 1951, p. 73. 
deria sem risco de anulação entre uns e outros..." (23) Eis aí, isto sim, um belíssimo aspecto de profundo sentimento de brasilidade da parte de Alvarenga, pois os crioulos e mulatos eram nativos, portanto como brasileiros lutariam com os irmãos, filhos da mesma pátria. Ele não visava apenas aquietar os ânimos quanto à possível revolta dos negros, (24) mas apontava uma solução imediata: a libertação dos brasileiros escravos. A dos cativos africanos seria uma segunda etapa. Havia, não há dúvida, uma posição firmada na qual borbulhava o senso emancipador, embora a prudência exigisse se pinçasse, com perspicácia as possíveis desordens ante uma medida drástica. Esta poderia tornar a sociedade vulnerável a pressões que deviam ser olhadas sem contempto do bom senso (25). Oiliam José faz estas condições repletas de acuidade: "Pela primeira vez, no Brasil um pugilo tão credenciado de homens versava, pois, o dificílimo e explosivo problema da emancipação dos escravos negros. Faziam-se, assim, os conjurados os pioneiros absolutos dessa batalha que, um século depois, seria ganha pelos defensores da sofredora gente oriunda dos escaldantes territórios africanos, onde uma forma pior de escravidão já torturava os negros: a escravidão não mitigada pelos sentimentos inspirados na doutrina cristã e capitaneada pelos desumanos régulos, que nem sequer recuavam diante do crime de trair e vender como escravos os próprios irmãos de raça". (26) Há, porém, outros pormenores que devem ser realçados. O Pe. Toledo foi bastante explícito quanto a este assunto escravocrata. Era menos dependente das injunções econômicas, apesar de ser fazendeiro poderoso. Ele sugeriu ao Coronel Francisco Antônio de Oliveira Lopes, possuidor de escravos, "que os desse, que bem podia aprontar vinte e que um negro com carta de alforria na testa se deitava a morrer". (27) O Coronel não tinha esta antevisão: “... se libertasse vinte negros ficava

(23) - ADIM, IV, 398.

(24) - O receio de uma rebelião dos negros advinha também do fato de eles serem estrangeiros, africanos, e não brasileiros. O Desembargo da Relação do Porto, José Teixeira Coêlho, em 1780, na Instituição para o Governo da Capitania de Minas Gerais, faz esta afirmativa: "Neste mesmo ano de 1719 se descobriu e se evitou a sublevação que tinham maquinado, para a noite de quinta feira santa, os negros do Rio das Mortes, Furquim, Ouro Branco, Såo Bartholomeu, Ouro Preto e outras partes". Cf. José João Teixeira Coêlho, Instrução para o Governo da Capitania de Minas Gerais in: Revista do Instituto Histórico e Geográfico do Brasil, 3 a série, no 7, 19 trimestre de 1852, p. 330. Diogo de Vasconcelos discorre sobre os quilombos mineiros, núcleos fortíssimos, que reuniram pretos de outras capitanias. Cf. Diogo de Vasconcelos, História Média de Minas Gerais, Belo Horizonte, Editora Itatiaia Limitada, 1947, p. 179-190.

(25) - Pela declaração do Dr. José Álvares Maciel se vê como os diversos ângulos do problema foram levantados com muita sapiência e numa demonstração do alto nível de competência da liderança revolucionária.

(26) - Oiliam José, Tiradentes, Belo Horizonte, Imprensa Oficial, 1974. p. 72.

(27) - ADIM, II, 53 . 
sem ter com que trabalhar". (28) O Coronel estava agarrado ao status quo, não obstante ser um dos membros importantes do movimento revolucionário. $\mathrm{O}$ Pe. Toledo estava bem mais avançado, pois sentia a necessidade da destruição imediata de um dos sustentáculos do colonialismo. Patenteava que estava imerso não num mito, mas que vivia em profundidade novos tempos. Mais impregnado de humanismo, faz luzir uma consciência histórica apurada: a servidão devia desaparecer sem tardança. Tratava-se para ele de "separação da colônia, mudanças institucionais políticas e reorganização da sociedade em novas bases". (29)

Que os líderes da revolução de 1789 pregassem a abolição, parcial ou total, da escravatura era algo lógico. Seria paradoxal que estivessem a proclamar com Alvarenga a "liberdade ainda que tardia" -libertas quae sera tamen; ou com Cláudio Manoel da Costa a lançar este belo lema: "ou liberdade ou morte" -libertas aut nihil e admitissem simultaneamente o cativeiro. Como Tiradentes, que "reclamava para si ação de maior risco... percorria as ruas acompanhado de alguns sequazes, aos gritos de Viva a Liberdade", (30) se eles não estendiam estas prerrogativas a todos os cidadãos? Incompatibilidade completa, radical surdiria entre tal clamor e a triste condição dos que não tinham seus direitos reconhecidos.

No programa dos lúcidos condutores dos acontecimentos de $1789 \mathrm{em}$ Minas Gerais, estava o término do escravismo e isto muito contribuiu para que, menos de um século depois não mais houvesse esta indesejável dependência humana em plagas brasileiras.

As considerações sobre a visão que os Conjurados Mineiros tinham do escravismo comportam uma outra faceta importante, a saber, o relacionamento deles com os escravos.

O valente pardo Alexandre da Silva pertencia ao Pe. José da Silva de Oliveira Rolim e the foi extremamente dedicado. Como mostram os Autos de Devassa (31) o Capitão Manoel da Silva Brandão, Comandante do Destacamento do Tejuco, fora designado para prender o Pe. Rolim e o irlandês Nicolau Jorge. Este foi localizado e aprisionado. O referido sacerdote fugiu. Na arraial do Itambé, se escondeu nas propriedades paternas. Até lá foi ao seu encontro seu servo que se colocou às suas ordens.

(28) - Idem, ibidem.

(29) - Carlos Guilherme Motta, Atitudes de Inovação no Brasil, - 1779-1801

- Lisboa, s/d., p. 115.

(30) - Ernesto Ennes, Autos Crimes contra os réus eclesiásticos da Conjura§ão de Minas Gerais in: Anuário do Museu da Inconfidência, Ouro Preto, 1952, p. 20.

(31) - ADIM, III, 125 e seguintes. 
Descoberto, escapou novamente com a eficiente cobertura do mesmo Alexandre. De acordo com o ofício do Visconde de Barbacena, datado de 15 de julho de 1789, era de "estatura ordinária, grosso de corpo, claro, cabelo atado..." (32). Meses depois seria finalmente detido com seu criado, melhor dizendo, seu amigo inseparável. Com ele estiveram no Rio Pardo, dez meses na Comarca de Sabará, depois no Rio de Janeiro (33). Aliás ficou registrado ser ele para o Pe. Rolim "o escravo de sua maior estimação, tanto assim, que era, quem the escrevia as suas Cartas, como tem confessado e está verificado; e visto que ele Respondente sabia dos seus segredos..." (34). No último ataque, acabou sendo baleado ao defender seu amo. Ficou preso no Rio de Janeiro. Foi submetido a duros interrogatórios. Foi ouvido quatro vezes. (35) Em momento algum incriminou seu patrão. Ele foi absolvido pela sentença de 19 de abril de 1792, porque não incorrera em crime contra Portugal. Suas prudentes respostas não prejudicaram, em si, nem a ele, nem ao Pe. Rolim. Ele era apenas um pagem obediente, digno de encômios. (36)

(32) - Anuário do Museu da Inconfidência, MES, 1953, p. 74.

(33) - ADIM, II, 336.

(34) - ADIM, II, 342.

(35) - ADIM, II, 335-348.

(36) - Eis o texto do Auto de Devassa: "Contra este Réu se não prova mais do que haver escrito por ordem de seu Senhor o Padre José da Silva de Oliveira Rolinı as cartas a folhas 36 e folhas 37 da devassa de Vila Rica a Domingos de Abreu Vieira, e haver acompanhado ao dito Padre em todo o tempo, que este esteve refugiado na serra do Itambé, circunstância que não induzem prova de ser entrado no levante, nem sabedor dele; porque não consta, que o dito Padre the comunicasse a este respeito coisa alguma, nem nas ditas cartas se faz menção do levante e a companhia que fez ao dito Padre no mato, foi um ato indiferente, e próprio da servidão a que estava adstrito que não basta para se presumir ser este Réu ciente da causa verdadeira do homízio; e mais consta por declaração de outro escravo Joaquim seu parceiro a folha 10 verso de apenso 20 da devassa de Vila Rica, que este Réu Alexandre nunca saíra do mato, nem nesse tempo escreveu carta alguma ao dito Padre e ainda que conforme a direito fica incurso na mesma pena tanto o que comete o delito, como o que é consente; procede esta disposição quando o consentidor coopera com o agente positivamente dando causa eficaz e propínqua para o delito de forma de modo que faltando esta circunstância não bastam os mais fatos indiferentes praticados por aquele que tinha obrigą̧ão de os prestar se com eles não excita o delito, nem foram obrados com ânimo de facilitar e mover", cf. ADIM VII, 130-131. É lógico que tudo isto valorizou este homem brioso e é o caso de se pensar se o interesse monetário no mesmo não forçou estas justificativas, pois foi posto à venda pelo Edital de 25 de Abril de 1792 supervalorizado. Cf. ADIM, VI, 107. Acabou indo para a companhia do Capitão Antônio Ribeiro de Avelar pela alta quantidade de cento e cinquenta e três mil e seiscentos réis $(153 \$ 600)$. Cf. ADIM, VI, 110. Leve-se em conta que João Rebolo foi arrematado por setenta e quatro mil e cem réis $(74 \$ 100)$. Cf. ADIM, VI, 322, Cypriano, do Côn. Luiz Vieira, por trinta e cinco mil réis $(35 \$ 000)$. Cf. ADIM, I, 324. O pardo João, do Coronel Francisco de Paula Freire de Andrade, por cento e cinquenta e um mil réis (151\$000). Cf. ADIM, I, 325. Observe-se en passant que, não obstante na ótica jurídica e na linguagem oficial estas horrípilas transações 
O mesmo deu-se com Joaquim, de nação nagô, que também foi capturado com Pe. Rolim. (37)

Não menos serviçal foi Nicolau, servo de Domingos de Abreu Vieira, (38) que acompanhou seu senhor nas prisões de Vila Rica e do Rio de Janeiro, indo inclusive com ele para a colônia luso-africana de Angola. Se o mencionado conjurado fosse um déspota, um desalmado, não teria insuflado tamanha adesão a um cativo. Foi recompensada sua fidalguia e generosa deferência pois, para poder seguir para a África, um amigo do Tenente-Coronel Domngos o arrematou e, em seguida, o libertou. Segundo Lúcio dos Santos, no exílio, "pouco viveu o conjurado, já velho e doente, sempre amparado pelo seu escravo e maior amigo, que lhe cerrou os olhos e abriu a cova, plantando sobre ela uma cruz tosca de madeira, para proteger a sepultura do morto, na terra estranha e atrair sobre ele a misericórdia de Deus". (39) Página comovedora que alardeia ter tido o período escravocrata, não obstante suas mazelas, instantes luminosos. Laços indestrutíveis se estabeleceram entre muitos donos e seus súditos, num convívio amistoso e prenhe de muita afeição.

Tomás Antônio Gonzaga foi noticiado por um de seus comparsas de que a conspiração fora detectada pelas autoridades. O misterioso encapuçado que, na noite de 17 ou 18 de maio de 1789 , andou pelas ruas da capital de Minas, the deixou uma mensagem oral com a negra mina, sua serva Antônia, pessoa dotada de profunda discrição.

Tudo isto prova haver cativos devotados, merecedores de total e irrestrito respeito e que eram distinguidos, exatamente, pelos dotes de virtude e pelo valor moral que ostentavam.

Certas obras amplamente divulgadas inoculam a impressão de que, na era colonial, só existiram perversidades, traições, ódios, perseguições, idiossincrasias que obstaculizavam qualquer possibilidade de simpatia entre ele-

fossem de tres - coisas, para muitos a conotação era a compra da prestação de serviços. Para diversos intérpretes abalizados, na mente de muitos esta noção de pro labore era nítida. Assim o preço correspondia aos esforços laboriosos da pessoa, que receberia, além do mais, vestuário, casa e alimentação. Hoje em dia, há um modo de se expressar corrente que daqui a séculos poderá ser malinterpretado, por causa do verbo vender. É abrir a parte esportiva dos jornais e lá estão manchetes como estas: Tal jogador foi vendido por tantos milhốes de cruzeiros. Clube $\mathrm{X}$ não porá seu craque à venda. Este atleta é inegociável. O que está sendo vendido são os serviços que serão prestados.

(37) - ADIM, II, 354.

(38) - ADIM, VII, 41.

(39) - Lúcio José dos Santos, op. cit., p. 450. 
mentos de classes diferentes. Numa generalização condenável, para incentivar o indesejável regime, apresentam os senhores como sádicos opressores e os cativos como inimigos mortais.

Vários foram os escravos ouvidos. Otima oportunidade para descarregarem sobre seus amos toda sorte de rancor que porventura tivessem armazenado no seu subconsciente, increpando-os violentamente. No entanto, vemos que tal não aconteceu. Entre os denunciantes não apareceram escravos, embora muitos deles fossem perpicazes e ativos. Alguns sabiam ler e escrever. Na Fortaleza da Ilha das Cobras, no Rio de Janeiro, estiveram recolhidos, além do citado Nicolau, preto crioulo, Cypriano Cabra, escravo do Côn. Luiz Vieira da Silva; Manoel, preto crioulo, do Coronel Francisco Antônio de Oliveira Lopes, João pardo e João Preto, de nação Rebolo, do Tenente-Coronel Francisco de Paula Freire de Andrade. (40) Foram avaliados e vendidos em praça pública. Eles poderiam ter arrasado seus chefes.

No documento que o desembargador Francisco Luiz Ålvares da Rocha leu na sala do Oratório, a 19 de abril, reafirma-se o pensamento de Alvarenga, fazendeiro abastado, possuidor de engenhos de açúcar, minas de ouro e cerca de duzentos escravos, o qual dizia, ao alegar Álvares Maciel "que havia pouca gente para a defesa da nova república, que se desse liberdade aos escravos crioulos e mulatos". (41)

E que somente indivíduos do porte de Joaquim Silvério dos Reis tinham aos servos como ralé da sociedade: "última classe de gente desta terra como são negros e mulatos" (42) e, assim, thes impingia o menoscabo e toda espécie de maldades.

Pode-se, portanto, concluir que os con-jurados de 1789 perceberam os erros de uma engrenagem sócio-econômica execravel e desejavam uma nova ordem social na qual o escravismo seria banido.

(40) - ADIM, I, 309.

(41) - Ernesto Ennes, op. cit., p. 32.

(42) - ADIM, I, 25. 